\title{
INVENTÁRIO DE UMA (DES)EDUCAÇÃO MUSICAL
}

Eduardo Guedes Pacheco ${ }^{1}$

\section{Resumo}

Este inventário compõe a Tese de Doutorado Por uma (Des)Educação Musical, trabalho defendido no programa de Pós Graduação em Educação da Universidade Federal do Rio Grande do Sul em dezembro de 2011. Por sua vez, este trabalho também faz parte do Observatório da Educação Escrileituras - Um modo de ler e escrever em meio a vida, projeto aprovado no edital 038/2010 do Observatório da Educação do MEC, vinculado a CAPES e ao INEP e que tem a coordenação geral realizada pela Prof. Dr. ${ }^{a}$ Sandra Mara Corazza. O ensaio escolhe o prefixo (des) como ato de criação e o coloca à disposição de proposições entrelaçadas com a Educação Musical, tomando a filosofia da Diferença como intercessora e propulsora de processos composicionais ligados a Música e a Educação.

Palavras-chave: Educação Musical; Música; Educação

Entre tantas funções atribuídas aos anseios educacionais, podemos destacar os esforços concentrados em apresentar um conjunto de informações e conhecimentos que, por serem considerados por demais importantes, compõem as propostas curriculares dos espaços que têm por objetivo ensinar. São educacionais também aqueles lugares que não pertencem à rede formal de educação, mas buscam, através da organização de espaços, oferecer o contato com situações que provoquem ensinamentos. Nas escolas regulares, ensinar as letras, os números, as histórias, as artes, mesmo que esses últimos conhecimentos não ocupem o mesmo espaço nem a mesma importância nas ações desenvolvidas. Ou ainda, nas entidades religiosas, ensinar para a alma os caminhos de uma vida saudável. Eventualmente, esses ensinamentos tratam do corpo, de seus movimentos e limites e ainda tem a arte como foco principal das

${ }^{1}$ Doutor em Educação, Professor Adjundo da Universidade Estadual do Rio Grande do Sul. Endereço :Rua Barão do Triunfo, 685/301, Bairro Nossa Senhora do Rosário, Santa Maria - RS, Brasil. E mail :edupandeiro@gmail.com 
ações educacionais. As diferenças entre escolas, associações comunitárias, organizações não governamentais e entidades religiosas se manifestam nas escolhas dos conteúdos e informações. Também o nome dos responsáveis pela condução dos trabalhos pode mudar de lugar para lugar. Por exemplo, nas organizações não governamentais, encontramos os educadores sociais. Nas escolas, professores, coordenadores, diretores. Nos templos religiosos, são os pastores os responsáveis pela formação. Por sua vez, existe um aspecto que estabelece sintonia entre esses espaços educacionais: o primeiro deles se refere a tratar da infância como tempo de passagem, de lugar a ser preenchido. Necessidade de cuidados para que a criança possa se tornar, no futuro, um adulto saudável. Para que tal promessa possa se concretizar, é preciso que essa infância receba uma educação compatível com o trajeto que deve ser realizado. Para isso, a formação educacional deve garantir que essa infância entre em contato com os conhecimentos validados pela humanidade, que apresentados ao lado de valores que guiam as condutas dos seres no cotidiano permitam que as crianças possam aprender, ou melhor, crescer. A lição a ensinar àqueles que têm como trabalho aprender é voltar seus olhares às constâncias da vida, expressas nas diversas possibilidades de existência da nossa realidade. Todavia, esta é a única opção a ser explorada quando tratamos da educação? Existem possibilidades que buscam alternativas para essas escolhas? Seria possível, no lugar das condutas ditadas pelo pensamento científico, as quais tratam das ações educacionais, que pudéssemos pensar sobre aprender, tendo a surpresa e o inesperado como mote principal? Ensinar sobre o mundo, pensar sobre ele, exige que esse caminho seja trilhado a partir da vontade de falar sobre o que já foi dito? Questões como estas possibilitam que muitas respostas sejam elaboradas. É possível afirmar que elas só serão acrescidas de valor se puderem possibilitar a elaboração de respostas distintas e ímpares, que se manifestem como possibilidade de relação com uma pergunta que não possui, na sua formulação, o autoritarismo de se permitir ser respondida por um conteúdo pré-determinado e único. Entendendo essas questões como disparadores, elementos provocadores de curiosidades, este texto encontra alegrias em elaborar uma (des)educação que tem na música e na infância seus focos de atenção. Contudo, a opção por apresentar o "des" à frente de uma palavra tão cara às relações sociais na contemporaneidade provoca certo desconforto, por isso merecedora de atenção. A palavra (des)educação pertence um a conjunto de palavras designadas, pelo poeta Manoel de Barros (2003), como "palavras da fonte". Tem ela como característica exercer maior simpatia pela desordem das falas infantis do que pelas ordens gramaticais. Diferentes das palavras de tanque, que são estagnadas, estanques e acostumadas, 
as palavras que vêm da fonte possuem a leveza e a agilidade de não se acostumar com sentidos e informações estabelecidas. Buscam sempre novas cores, novas texturas e, como crianças, estão acostumadas a inventar sobre a vida. Palavras da fonte também podem ser chamadas de palavras curiosas. Sua presença não estabelece uma explicação, pelo contrário, sua aparição é a provocação para a busca de lugares desconhecidos, é o convite para trilhar caminhos ainda não percorridos e lançar olhares para o inusitado, tendo a atenção como principal guia desta caminhada. Porém, a caminhada proposta tem como característica a eleição de um olhar atento muito específico: o de voltar a atenção ao (des)prezível, àquilo que foi jogado fora, ou mesmo, que não foi eleito para receber cuidado. Os desprezados têm uma vantagem sobre as coisas prezadas: a oportunidade de livrarem-se das personalidades a que foram entregues. Assim como as "latas precisam de muitos anos para perder todos os ranços e artifícios da indústria, e só depois de esquecidas na Terra terem o prazer de namorar com as borboletas" (BARROS, 2003), as coisas desprezíveis, pela falta de atenção à qual estão submetidas pela maioria das pessoas, estão aptas a serem despersonalizadas, e a partir de novas relações ganham novos nomes, novas funções, experimentam novas relações.

Aqui, (des)educar encontra uma fonte para a possibilidade de criação. Busca, neste olhar atento e curioso, o que é da ordem do "desprezível" na música. Por exemplo: numa escala maior, o quinto grau, ou seja, a dominante, tem a função de, além de ajudar a definir a tonalidade, servir como um trajeto seguro para que a tônica possa soar novamente. (Des)educar é, através da atenção e da curiosidade, tirar de um conjunto de notas suas qualidades primeiras e inventar lugares onde as relações dos sons passam a ser um (des)objeto da música. Ou seja, todas as forças que garantem a sua personalidade possam se esvair para dar espaço a que outras intensidades ali se instalem, e que estas sonoridades não possam mais ser identificadas, unicamente, pelo que antes soavam. Também é característica de um (des)objeto estar sujo de todas as coisas que o envolvem. Assim, um (des)objeto musical está sujo de tudo que o envolve. Uma sonoridade desobjetada nunca é só uma sonoridade. Ela carrega consigo esguichos de toda a vida em que está inserida, não sendo possível que se expresse sem as marcas dessas relações, acontecendo o mesmo no caminho inverso.

$* * *$

A vida é tocada pelas sonoridades, assim como as sonoridades são tocadas pela vida. Crianças gostam de tocar suas vidas. Crianças gostam de cantar e tocar tambores. Basta uma pequena melodia entoada por vozes ou tambores para que a vida assuma cores singulares, 
cores sonoras. O (des)nome desta música é (des)educação. A intenção não é a criação de novos lugares fixos para as sonoridades, para as relações entre infância e música nos espaços educativos, mas produzir possibilidades que, por sua intensidade, possam provocar nas pessoas que participam desse movimento o encontro com algo que ainda não tinham vivido. O (des)sobrenome da (des)Educação é Musical, mas também poderia ser Improviso, pois a proposta aqui é a de estabelecer afinidades com o mundo. "Improvisar é ir ao encontro do Mundo, ou confundir-se com ele e, a partir desse encontro, experimentar o percurso costumeiro de uma criança, enxertar-se ou se por a germinar linhas de errância, com volteios, nós, velocidades, movimentos, gestos e sonoridades diferentes" (DELEUZE; GUATTARI, 2005). Os espaços educacionais, neste texto, não são compreendidos como lugares fora da vida. E como tais, estão sujeitos às provocações impostas por esta relação com as sonoridades, em especial com aquelas inventadas - as novas composições. Improvisar é assumir riscos de desestabilizar as forças presentes antes do seu acontecimento. Ao realizar este movimento, todas as outras forças que fazem parte dos espaços nos quais o improviso está sendo realizado também são captadas pelas linhas de errância. No contexto das ações educacionais, isso significa fazer experimentar outras intensidades, outras velocidades entre as relações com o conhecimento: as relações com o espaço físico e, principalmente, as relações de poder que podem ser expressas pela própria música escolhida para preencher os espaços de educação, como também a hierarquia estabelecida entre alunos, os seres da infância e professores representantes dos adultos.

$* * *$

Como uma música pode exercer poder? Que relações de poder uma música apresenta ao ser exposta ao mundo? Para a elaboração deste trabalho, alguns traços dessa relação compõem este momento. O primeiro deles é o mais simples. A partir das relações físicas entre ondas vibratórias é possível estabelecer formas de comunicação com o que, comumente, chamamos de notas musicais. Se tomarmos como exemplo as sete notas da escala diatônica, as relações entre as ondulações apontam para um tipo de comunicação entre as notas dessa escala. Por exemplo, a nota sol (quinta nota da escala de dó maior) tem uma aproximação com a nota dó (primeira nota da escola de dó maior). Ao soar, ela provoca a vontade de que a nota dó seja tocada. Assim, a nota sol, a dominante da escala de dó, pede, fisicamente, para que essa nota seja executada, provocando uma sensação de repouso. Se pensarmos nas escalas maiores, as quintas notas de cada escala possuem um grau de importância maior que as outras, e assim são utilizadas nas composições. Existe uma relação de poder entre a quinta nota da 
escala e as demais notas - uma hierarquização. A imensa maioria das músicas que fazem parte do cotidiano da vida escolar exprime essa relação de poder entre as notas das escalas musicais. O próximo exemplo trata das escolhas feitas pelos compositores no que se refere a como tratar melodias, harmonias e ritmos. Estes são três elementos que podem fazer parte de uma composição musical. Não são exclusivos, nem únicos, mas representam a forma como boa parte da música no ocidente é realizada. Nessas composições, o ritmo tem como principal função ser o responsável por conduzir a melodia, a qual pode estar inserida dentro de um contexto harmônico ou não. A opção feita pelos músicos europeus é de que a busca pela elaboração da melodia guiasse as experimentações no campo da composição. Essa escolha coloca o ritmo com traço de segundo plano, tendo serventia, somente, para carregar a melodia nas obras. Essa opção invade todo o fazer musical do ocidente. Diferentemente, os povos africanos elegeram o ritmo como principal traço de suas composições musicais. O que interessa é a possibilidade de criação de tramas de timbres e polirritmias. Por tudo que sabemos da relação entre o ocidente e os povos africanos, é possível constatar na história que o ritmo, além de ser entendido como um instrumento de apoio à melodia, representa a expressão de um povo tratado como menos capaz, menos humano.

Essa relação expressa, no fazer musical, uma hierarquização entre as forças que compõem uma obra musical. Portanto, (des)educar pode ser compreendido como a vontade de criar situações em que essas relações possam ser desestabilizadas. Promover um improviso em direção ao mundo da própria música. Possibilitar que a execução de uma tônica permita que outra nota seja executada. Não se trata, aqui, de buscar substitutos para essa relação, mas criar uma nova resposta e, quem sabe, fazer dessa resposta a elaboração de algo que não se espera ouvir. Improvisar com peles de tambor - que, por suas características, não produzem afinação determinada e, por isso, estão livres das afinações preconcebidas pela natureza. Fazer desse improviso a possibilidade de criação de personagens que, ao se encontrarem com os demais elementos que compõem a escola, permitam um deslocamento das posições assumidas, jogando-as para lugares que ainda não foram ocupados. Esse improviso, essa criação de músicas ainda não inventadas, ainda não ouvidas, é tomado como uma possibilidade (des)educacional.

$* * *$

Ao tratar das hierarquias no contexto musical, realizo a tentativa de criar cenários no qual a (des)educação Musical passa a ser apresentada como a vontade de elaboração de um 
movimento minoritário no contexto educacional. Para Deleuze e Guattari (1977), uma arte menor é aquela que desterritorializa a arte maior - faz gaguejar a língua dentro do próprio idioma. A aproximação com esse conceito expressa, em primeiro lugar, uma forma de questionar as relações de poder expressas nas músicas e nas ações educacionais. Depois, proporciona a imensa alegria e gosto pela criação como opção de relação com a vida, como possibilidade de problematização dos espaços escolares. Ao tratar da educação como uma fatia da vida, que tem no poder formas de inviabilizar experimentações nas relações entre as pessoas, as artes e a própria vida, a (des)Educação Musical tem “[...] a função política do teatro - e da arte em geral" que é de "[...] contribuir para a constituição de uma consciência de minoria" (MACHADO, p. 70, 2010).

Ela pode tornar presente nas educações uma música que busque burlar as regras e as formas de hierarquização que acabam contaminando não só a própria possibilidade de invenção em arte, mas também todos os meios que compõem estes espaços onde essa manifestação se faz presente. Para tanto, (des)educar é atuar com as linhas (des)prezadas, jogadas fora. Aquelas que, por não servirem às regras ditas cultas, não recebem atenção e são tratadas com menos importância. Linhas que não servem às forças que estabelecem as formas de poder e exclusão daquilo que não é entendido como sendo da norma. Para isso, os (des)prezados, sejam os acordes musicais jogados fora, aqueles que expressam muito mais as diferenças do que as consonâncias, os instrumentos que normalmente são colocados na parte detrás dos grupos instrumentais, as notas que não são dominantes, passam a ocupar lugares da mais alta atenção. Trazer à cena coisas que são (des)prezíveis, não para exaltar suas identidades, mas para usar as potencialidades que essas linhas possuem. Essa força tem uma forma de ser diferenciada, pois sua existência também se guia pela ausência de todos os tributos que os prezados devem carregar. Nesse movimento, os desprezados serão tratados de modo que sejam (des)objetados, criando assim uma conjunto de linhas que, pela intensidade de suas movimentações, acaba contaminando também os prezados. Dessa forma, por contaminação, prezados e desprezados são convidados a (des)objetar suas existências, livrando-se das personalidades, das incumbências a que foram submetidos pelos deveres, poderes e normas. (des)educar é (des)objetar as músicas que, em maior ou menor medida, fazem parte da vida dos educandos. Por isso, (des)educação dusical tem (des)nome - ela não busca fixar lugares, nem estabelecer regras às quais possam ser seguidas. O que ela deseja é (des)fazer o normal, seja a norma (BARROS, 2003). 
INVENTÁRIO DE UMA (DES)EDUCAÇÃO MUSICAL

No contexto da (des)educacão musical, o desperdício não é bem-vindo. A vida não deve ser desperdiçada. Ela é alimento para todas as possibilidades (des)educativas, assim como é local e foco de criação. Portanto, músicas e infância são potências que nutrem as mudanças que a relação com a arte pode promover nos espaços educacionais. Nesta perspectiva, todas as forças que não são musicais, tudo quanto não é sonoro passa a fazer parte desse turbilhão (des)educativo - nada é desperdiçado nas ações que colocam a música como possibilidade de pensamento e criação nos espaços educacionais. Por exemplo: as regras que determinam como os corpos devem se movimentar nos espaços educacionais não são tratadas como empecilhos nas "musicagens" (des)educativas ; ao contrário: elas podem servir como alimento à elaboração das fugas aos confinamentos. Sempre que a criança cantarola ela dá um salto melódico com sua voz - o seu corpo salta junto. É nesta hora que o canto entoado nas regras serve de palco à criação de situações inusitadas. A regra produz nos corpos - ou pelo menos busca produzir - um tipo de confinamento ao qual o ser confrontado pela melodia inesperada da canção produz, na relação com a mesma, uma força que sem a presença da regra não aconteceria. As ações (des)educacionais não buscam confrontos com as situações da vida, mas trocas. Todas as forças que são apresentadas nas situações do cotidiano possuem potências, mesmo as que não nos trazem alegria. Entretanto, desperdiçar esse encontro é jogar fora o que é da contingência do viver. $O$ filtro (des)educativo não caminha na direção da limpeza, não busca aquilo que é entendido como limpo, saudável, mas o que a vida contém nas suas mais altas possibilidades. Claro que não teremos, muitas vezes, forças para suportar toda a carga de uma vida. Isso impediria o encontro. Por outro lado, buscar formas de trocas com estas potências significa que o filtro desta relação não tem uma necessidade de hierarquizar os encontros. Sem hierarquias. Por sua vez, o filtro (des)educativo funciona com outras intenções: busca qualidade de expressão, criação e não se nega a ser tocado por todas formas e coisas que, em determinados casos, são abundantes, e que noutros se apresentam em menor intensidade. Uma (des)educação musical age nos espaços educacionais, porque nestes lugares sente a necessidade de estar. Perguntas poderiam ser realizadas, como por exemplo: por que a educação? Pela simples alegria. Pela opção de escolher esta fatia de vida como espaço de encontro com a vida que acontece na educação. Isto não implica em colocar este lugar numa posição privilegiada em relação a outros, mas apenas exprimir uma simples alegria: a de estar em relação com a infância nas condições que se encontram professores e alunos e perguntar: as relações desta vida podem ser transformadas? A vida que compartilham 
infância e aqueles que necessitam ensinar pode assumir possibilidades não experimentadas? Os que desejam ensinar e os que desejam aprender podem compartilhar lugares sem distinções hierárquicas? Podem ser inventadas formas de relação entre esses atores? Alegrias não são egoístas. A presença de uma não exclui as possibilidades de outras. Neste caso, a presença da primeira serve como guia para a segunda,ou seja, o prazer de buscar encontrar nas relações com a vida aquilo que não está disponível, aquilo que não é visível, audível. Por isso, (des)educar se vale da arte para conduzir suas ações. Contaminar as educações não com a "reprodução ou invenção de formas" (DELEUZE, 2006), mas com a vontade, a necessidade de captar as forças que explodem da/na vida. Outra beleza. Não se trata mais de estabelecer um clã de artistas, de músicos, já que a música não tem por exclusividade o som como elemento principal. “A música, portanto, não é um assunto apenas dos músicos, na medida que ela não tem por elemento exclusivo e fundamental o som. E sim o conjunto das forças não sonoras que o material sonoro elaborado pelo compositor vai tornar perceptíveis, de tal maneira que poderia até mesmo perceber diferenças entre essas forças, todo o jogo diferencial das forças" (DELEUZE, 2006). A arte é a possibilidade de produzir diferenças. (Des)educar é concentrar energias na busca por tornar sonoro aquilo que não é. Ao tomar do filósofo esse entendimento sobre as possibilidades da arte, cabe afirmar que, ao fazer soar aquilo que não é sonoro, criam-se possibilidades dos espaços educacionais se constituírem em espaços de captação de forças. Dada essa possibilidade com a arte, pode-se pretender que esse movimento contamine todos os outros aspectos que compõem os lugares escolares, com essa perspectiva de relação com a vida. Tornar visível, assim como na pintura, aquilo que não o é. Assim, esses lugares poderiam deixar de se configurar como espaços de informação, aos quais a avaliação se compromete em verificar quantidades. Podemos perguntar: isso faria nascer o que nesses espaços? Aqui se encontra um dos fundamentos que fazem parte da procura por uma (des)educação. Ao serem tratados pelo viés da arte, esses espaços estão livres para ser reinventados. Essa reinvenção, ao lidar com o que ainda não é da ordem musical, também é inesperada, imprevisível. (Des)educar constitui um caminho artístico, ou melhor, de realização em arte, a qual tem como principal foco a produção de sensações a partir das suas criações. O próprio (des)educar musicalmente tem chances de se tornar arte, na medida em que, além do trabalho realizado com música, pode produzir a possibilidade de fazer surgir, em educação, forças invisíveis da ordem dessa prática. Para tanto, uma dose generosa de atenção se faz necessária. Assim como qualquer fatia da vida, os espaços educacionais estão carregados de situações, enunciados e leis, e de tantos outros aspectos que a compõem. Os 
mais diversos jargões, palavras de ordem e clichês são instrumentos de acomodação das possibilidades do pensamento. Ao tratarmos de educação, estes aspectos preocupam de maneira especial. Criar uma (des)educação convoca para que esses aspectos sejam "raspados" das cenas, das partituras, dos instrumentos e das relações, sejam elas pertencentes a que ordem for; sejam também raspados das próprias condutas dos produtores das ações (des)educativas.

$* * *$

Alguns procedimentos são simpáticos ao desejo de realizar a (des)eduação musical. Um desses procedimentos, de grande importância, assumido por aqueles que têm por alegria a busca pela criação, é o de se fantasiar com as máscaras daqueles que são caros na sua forma de propor o exercício do pensamento. Paul Valéry (1998) toma o pensamento de Leonardo da Vinci não para contar ou mesmo explicar ao mundo o que o grande artista fez, mas para criar, compor a si mesmo. Cuidado: não estamos falando da criação do eu da identidade, mas da criação de um eu do pensamento. Valéry usa a máscara desse gênio do Renascimento para pensar a vida. Assim Deleuze fez com Proust, Nietzsche, Bergson e Spinosa. O filósofo se fantasia desses autores para criar a sua própria forma de pensar. Uma (des)educação musical fantasia seus (des)educadores de compositores, instrumentistas, filósofos para criar seus pensamentos. Uma (des)educação musical coloca máscaras nas suas músicas. Todavia, aqui é proposto que esse procedimento ganhe um acréscimo nas suas realizações. O que se deseja é que uma aula use a máscara de uma composição. A fantasia a ser usada numa situação (des)educacional não é só dos autores, compositores, mas também de suas obras. O uso da fantasia não cabe somente à ordem das pessoas, mas também das ações, que neste cenário buscam se tornar criações. Eis uma ideia que é um dos motivos deste texto: usar as máscaras daqueles que têm nas suas criações e opções de pensamento a vontade e a inquietação de fazer das suas formas de criação uma busca pelo que não foi inventado. Alguns exemplos podem ser citados: Uma aula de música fantasiada de John Cage, título da aula: A sinfonia do Silêncio. Uma aula mascarada de Hermeto Pascoal, título da aula: O Porco e a Chaleira. Sandra Corazza, título da aula: Metainfancioritmica, polirritmias de uma infância por vir. José Miguel Wisnik, título da aula: As sonoridades de uma história ainda sem sentido. Ou ainda, vestir as máscaras das obras de intercessores escolhidos para realizar uma aula (des)educativa, como por exemplo: uma sagração primaveril das ritmologias e do pensamento percussivo. Entretanto, a utilização destsas máscaras não se limita à relação com este tipo de intercessor. 
Os grandes filósofos, os músicos com reconhecimento histórico, os professores famosos pelas suas pesquisas e obras são (des)reguladores dos sistemas educacionais convencionais.

(Des)educar propõe que as máscaras usadas sejam também daqueles que fazem sons com a boca e andam de pés descalços. Fantasias daqueles que têm no ritmo uma arte de brincar com o som. Os que se relacionam com a vida através das suas (des)importâncias e fazem música (des)importante - inútil, para alguns. Isso é "um prato cheio" quando se trata de música, pois o seu mundo é recheado de coisas importantes. Por exemplo, o maestro é muito importante. Não seria exagero afirmar que é mais importante que os músicos da orquestra. Assim como o violino é mais importante que a viola que, por sua vez, é mais importante que o trompete que, na linha sucessória, tem mais importância que a percussão. Realizar uma (des)educação que tem a música como seu material de trabalho se configura em criar métodos de procura, de investigação que tenham como principal objetivo de pesquisa as (des)importâncias musicais e educacionais. Assim, todas as relações que atribuem valores, muitas vezes entendidos como naturais e imutáveis, podem ser lugares de transformação. A intenção é de que as normas sejam (des)normalizadas; quem sabe, tomar todas as importâncias e através destas (des)normalizações possibilitar que suas personalidades possam ser (des)educadas ao ponto de se tornar (des)importantes, e alimento para práticas (des)educativas produtoras de criações sonoras e educacionais.

Alguns compositores realizam (des)importâncias na elaboração de seus trabalhos. Um deltes é o músico, professor e compositor Carlos Eduardo Di Stasi. Em seu trabalho de doutoramento - Representantions of Music Scrapers: The Disjuncture between and complex in the study of a Percussion Instrument (1999) - Stasi busca problematizar as regras das normas entendidas como cultas nas suas composições, através do reco-reco, um instrumento entendido como um dos mais (des)importantes da nossa cultura, mas fonte para a criação de obras em que a música floresce de uma forma totalmente inusitada.

Se nas orquestras sinfônicas os instrumentos de melodia têm primazia sobre os instrumentos de percussão, os instrumentos de pele, entre eles as tumbadoras e a bateria, são merecedores de maiores glórias que os instrumentos de raspagem. O reco-reco que normalmente é um instrumento de acompanhamento passa a receber um tratamento que o coloca no lugar que é dedicado aos solistas, aqueles que ganham obras voltadas para que suas possibilidades expressivas possam ser extrapoladas. Ao realizar esta (des)importância, Stasi 
não traz à tona somente um instrumento que geralmente ocupa lugares de subalternidade nas relações musicais. Ele problematiza as normas de criação em música que têm como princípios diretrizes quase entendidas como naturais no fazer musical. Entre elas, podemos destacar a ideia de que o ritmo é o suporte para a melodia dentro de uma composição. Como o reco-reco não é um instrumento melódico, as composições têm, no ritmo, seu material. Mas outros aspectos também são invocados: a postura do corpo, o manuseio, os movimentos que são evocados para que o instrumento possa "cantar", as sonoridades criadas pelo compositor; tudo isso compõe um caminho inédito para a música, provocado pelo encontro com a (des)importância daquele instrumento. John Cage, em uma de suas peças mais famosas, realiza esta (des)importância. Uma das histórias do continente europeu nos mostra que as escolhas feitas para a música desde o século VI buscam tirar do fazer musical todo o tipo de som que possa interferir nos entrelaçamentos entre melodias e harmonias. Para isso, foram sendo criadas regras para que todos os sons que não fossem entendidos como musicais ficassem fora da música, assim como os lugares onde eles fossem executados . Podemos entender as grandes sinfonias como manifestos contra o ruído, onde toda a clareza e limpeza devem estar ao lado das fontes melódicas e harmônicas. As salas de concerto são a manifestação contemporânea dessa vontade. Esses lugares são arquitetonicamente projetados para que os ruídos de fora não possam interromper a música que está sendo executada ali. Também àqueles que não conseguem se colocar em postura de atenção e silêncio é sugerido não participarem desses rituais. Cage elege as (des)importâncias para compor seu 4' 33' música que tem como principais elementos o silêncio dos instrumentos e os ruídos que a platéia realiza ao se confrontar com um pianista que executa seu solo a partir da não produção de sons do seu piano. Aqui o (des)importante passa a ocupar o lugar privilegiado dos solistas e questiona, através da sua execução, toda uma história da música que tem como foco excluir os sons não musicais das músicas, bem como o privilégio dos músicos em realizarem música num concerto.

Apesar das forças que buscam colocar a infância em lugares determinados, meninos e meninas, muitas vezes, criam fugas para esses confinamentos. Essas forças têm ressonâncias com a criação musical. Outro compositor que busca na (des)importância alimento para a sua criação é Igor Stravinsky. Como todo o compositor da chamada música erudita, Stravinsky é herdeiro de uma tradição composicional já mencionada. Sua escolha, contudo, pela (des)importância proporciona o nascimento de obras musicais que colocam à prova, no seu 
caso em particular, formas de orquestração. Ao eleger (des)importâncias, entre elas o ritmo e a percussão, como traços protagonistas de obras como A Sagração da Primavera e Petruska, este compositor inaugura formas de relação com regras harmônicas, arranjos instrumentais, forma e estilo que produzem a inauguração de uma música sinfônica que ainda não tinha sido criada. A escolha das (des)importâncias pode ocorrer através de outros procedimentos. Tomar objetos e mudar a sua relação com a vida. Esses objetos podem ocupar determinadas funções nos cotidianos. Por exemplo, um rio que serve para matar a sede como local de deslocamento, ou ainda como fonte de alimentação. Uma relação de (des)importância pode ser realizada quando esse rio passa a ocupar a função de ser o instrumento principal de uma obra musical. A sua validação acontece não por suas importâncias, mas pela (des)importância de fazer música no contexto da vida de algumas pessoas. Por sua vez, a infância tem por prazer dedicar mais prazer às coisas (des)importantes e aos seres (des)importantes, prezar mais os insetos do que os aviões, as tartarugas do que os mísseis (BARROS, 2003).

O gosto pela (des)importância, neste texto, passa a ser entendido como força problematizadora e, como tal, força criadora. Para isso, criação não tem sintonia com colocar as formas em ordem. Pelo contrário, o gosto se expressa muito mais por brincadeiras do que pelo trabalho.

$$
* * *
$$

Ao tomarmos a infância como aquela que cria seus olhares para as coisas do mundo, tomamos emprestado as suas relações com essas coisas para compor esta (des)educação. Por isso, brincar e não trabalhar. Brincar diz respeito a eleger formas de tratamento, de relação, de criação, que se valham da capacidade de inventar e não informar. Criar coisas que possam ser (des)inventadas, possam mudar de lugar, onde a constituição dos sentidos a elas determinadas tenham a capacidade de serem (des)comparadas, assim como crianças fazem ao brincar com as palavras. O céu tem três letras, o sol tem três letras, o inseto é maior (BARROS, 2003). (Des)comparar é criar lugares de relação onde o que liga as coisas não acontece pelas lógicas que elegem as formas e os estados a partir de constâncias, na medida que possam expressar também constâncias. A (des)comparação das coisas (des)educativas escolhe o apreço pelas sensações que a criação pode expressar. Músicas, palavras, composições produzem (des)comparações pelo que soam, pelas sensações que afetam os corpos dos que estão envolvidos. A (des)educação musical, na medida que trata de sons, atribui forças sonoras ao que não é da ordem da música, atribui forças musicais aos espaços educacionais, 
INVENTÁRIO DE UMA (DES)EDUCAÇÃO MUSICAL

problematizando suas relações e suas regras a partir da criação de novos objetos, coisas, músicas. Busca criar outras possibilidades de existências educacionais. E faz isso também afetando os corpos. O que arte cria é um bloco de sensações (DELUZE, 1992), que são forças percebidas pelos corpos. Sonorizar o mundo é afetar a relação dos corpos com as coisas inventadas e com os próprios corpos envolvidos na criação desses blocos de sensações. Não é à toa que Nietzsche (1984) nos coloca que é perdido todo o dia em que se deixa de dançar. Ao produzir sensações, a arte faz com que o corpo saia das possíveis imobilidades, e a relação com as obras de arte produzam movimentos nos quais os corpos dancem com as trocas de intensidade, velocidades, cores, tonalidades, texturas que a expressividade artística provoca. Dançar é encontrar outras posições, outras formas de convívio, outros entendimentos sobre o que vida apresenta - fazer tudo como possibilidade de inventar uma vida ainda não vivida. A partir dessa escolha, de tomar a dança como possibilidade de música, ou seja, a criação musical como aquilo que afeta os corpos pela sua produção, a (des)educação musical, por ser da ordem das sonoridades, é por sua vez, na mesma intensidade da ordem da dança. O conhecimento envolvido nas relações (des)educacionais não tem a função de responder, acomodar, tranquilizar. Atenção, não se trata de ignorar a qualificação ou a importância dos conhecimentos anteriormente elaborados - o que muda é a relação com os mesmos. Um conhecimento já validado, já inventado vai servir de alimento, combustível para que a busca pela criação em música possa acontecer. Se dançar é fazer o corpo sair da imobilidade, fazer movimentar concepções, fazer música é colocar o corpo em movimento. Poderíamos afirmar que a (des)educação musical é fazer o corpo dançar as criações sonoras identificadas com a vontade de fazer soar o que ainda não soou. É afirmar que (des)educação musical faz música tendo o movimento dos corpos como fonte de "inspiração". Fazer soar os movimentos de corpos que sem a música não conseguiriam produzir sensações. Afirmar que a música, enquanto questão de movimento, é encontro de corpos distintos, peles heterogêneas. Encontro só proporcionado pelos movimentos. Movimento do encontro da pele da mão com a pele do tambor. Movimento da pele que vibra provocada pelo toque da pele da mão que, como a dança, sai de seu lugar de comodidade para provocar a presença de uma sonoridade que é fruto do encontro de diferenças.

$* * *$

Para realizar música, não basta que corpos e ouvidos se façam presentes. Não basta abrir a janela e ouvir música - o ouvinte não faz música (FERRAZ, 2005). É preciso mais que 
ouvir, é preciso mais que estar à frente dos ruídos: é necessário que se encontre as condições para que os ouvintes possam criar músicas, para que os corpos possam produzir músicas a partir de suas relações e encontros. Essas condições são dadas pelo plano de composição. Os ruídos, os movimentos, as paisagens, por si só, não compõem obras, melodias, ritmos. Os temas, os motivos, as texturas necessitam de um compositor. "Compor é desenhar um lugar, preestabelecer o que tem por lá, por algumas pedras, umas passagens, umas saídas, criar umas ranhuras que possam, quem sabe, atrapalhar uma visão que era clara" (FERRAZ, 2005, p. 97). No caso das ações (des)educativas, as salas de aula podem compor este plano - os lugares físicos onde as atividades acontecem são traços deste desenho. Outra característica se soma à possibilidade de que espaços educativos possam compor os planos de composição. Normalmente, quem é responsável pela criação no plano de composição é o compositor. No caso da (des)educação musical, não temos um compositor, temos um grupo de pessoas, professores e infância. A responsabilidade do professor é mais larga do que ser o responsável pela criação. Ele tem que criar condições para que a infância possa compartilhar da responsabilidade de criar o plano de composição. Assim, este plano que nasce na (des)educação musical se configura com um lugar para o exercício da criação, mas também para o exercício do compartilhamento das possibilidades de invenção musical. Essa situação faz com que as salas de aula possam se tornar elas mesmas material de criação. Nas aulas (des)educativas, fazem parte do material de composição musical, o espaço físico, as paredes, os ruídos oriundos do cotidiano, as músicas, as pessoas, os tempos, os humores, as cadeiras, os desejos, professores e a infância. Todavia, existe um material inédito que nasce do próprio movimento criativo exercitado dentro do plano de composição. Esse material que está por nascer - contingência da criação em arte - não se limita a produzir novas músicas. As novas músicas provocam o surgimento de novas pessoas. Participar como responsável pelo plano de composição cria condições para que os próprios envolvidos possam se tornar parte desse plano. Assim, professores e alunos que estão conduzindo os planos de composição de uma (des)educação musical estão inventando a si mesmos. São compositores de sons, educações, músicas de suas próprias vidas. Uma vida não mencionada, não prevista. Uma vida inusitada, pois resulta do compartilhamento das forças da criação em arte.

$$
* * *
$$

Como seria uma sala de aula da (des)educação musical? Se essa sala estiver tomada pela vontade de ser parte de uma composição, o desejo de organização é deixado de lado. As cadeiras de uma sala (des)educativa não são organizadas para garantir a funcionalidade do 
espaço físico. As cadeiras, as mesas, os instrumentos e tudo aquilo que pode fazer parte desse espaço está a serviço da criação, que convida aos que ali estão a experimentar sensações, saltos, passagens promovidas pelo plano de composição que, neste caso, é o espaço educacional. A sala de aula (des)educativa, enquanto plano de composição, é uma sala (des)regulada. Todas as coisas ali, todos os materiais, têm suas utilizações removidas das suas funções primeiras. Mas cabe ressaltar que esta remoção não é para outro lugar definido, ou mesmo a outra função determinada. A (des)regulação está ligada à possibilidade de fazer com que o material utilizado nas ações (des)educativas assuma uma existência inédita no contexto deste plano de composição. Se tomarmos como referência o livro de José Miguel Wisnik (1989), as sociedades, na medida em que foram criando e transformando as suas organizações de convívio, passaram a tirar do ruído o seu lugar de estabilidade, que era soar sem referências, ordens, regras. Com a vontade de estabelecer planos de organização e convivência social, os ruídos passaram a ocupar lugares indesejados. Assim, a criação musical, em especial a do Ocidente, constrói suas obras sonoras excluindo o ruído de suas composições. Tal atitude assume uma postura na qual a música ocidental tem como natural a exclusão de sons com frequências irregulares. Isso se torna a regularidade. John Cage, através de sua vontade de encontrar sonoridades ainda não provadas pelos seus ouvidos, promove uma (des)regularização da composição musical. No seu plano de composição - o qual dever ser organizado, como já o dissemos -. o ruído faz parte do material de composição musical. Aqueles sons que foram excluídos, agora são elementos de criação, estão (des)regulados de suas origens. Esta é uma boa oportunidade para especular sobre outro elemento voltado à elaboração de um conceito de (de)educação Musical: a possibilidade de emprestar forças sonoras àquilo que não é da ordem da música, criar condições para que os materiais utilizados possam se (des)personalizar de suas funções e utilidades primeiras para experimentar formas de ser e estar inéditas às suas existências. Se tomarmos o espaço educacional como matéria do plano de composição desta proposta, pode-se dizer: a (des)educação musical busca, através do esforço de tornar sonoras as forças que não são, criar condições para que as regras, as formas, os conceitos, os espaços físicos, as hierarquias, as propostas curriculares e as músicas possam se despersonalizar de suas funções e utilidades primeiras para experimentar estados inéditos às suas existências. Estas colocações também se referem às pessoas que estão envolvidas: aqueles que estão na posição de orientadores das situações e os que são alvo das ações educacionais, para o nosso caso, as ações (des)educacionais. Assim, a (des)educação musical 
PACHECO, Eduardo Guedes.

propõe, através da busca por experimentações sonoras proporcionadas pelo exercício da criação musical, que as pessoas envolvidas possam ser contaminadas pelas forças que regem a composição em arte ; que possam experimentar, em suas existências, o gosto pelo convívio com o inesperado, e que tal possibilidade se transforme num alimento não só à possível construção de uma prática docente "artistada", mas que também possa ser levado a outras fatias da vida, possibilitando um exercício contínuo de invenção de educações, músicas e dos seus "eus".

Com a intenção de realizar uma (des)educação musical, as palavras aqui expressas buscaram (des)praticar os olhares que estão voltados à educação musical nas escolas, igrejas, centros comunitários e todos os espaços que escolheram a infância e a música para propor situações de ensino e aprendizagem. Ao (des)praticar os espaços educacionais, as coisas que compõem esta educação têm seus comportamentos trocados. Notas dominantes vão experimentar outras soluções que não o repouso na tônica; maestros vão reger grupos musicais sentados atrás de todos os músicos; professores experimentarão sensações que não aquelas propostas por posições hierárquicas pautadas na autoridade do adulto sobre a infância; ritmos contaminarão peças musicais, assim como as relações entre diferentes meios que compõem as diferentes salas de aula - situações diversas , combinações, sonoridades, instrumentos e acontecimentos, tudo fruto dos processos de criação propostos.

Neste trabalho, a possibilidade de que as coisas educacionais tenham seus comportamentos trocados, que a educação seja contaminada por forças artísticas, recebe o nome de (Des)educação Musical. Para esta realização foram escolhidas pessoas que, através das suas vontades de criação, provocaram caminhos que convocam a arte para compor seus modos de pensamento, suas relações com a vida e, principalmente, nas formas escolhidas para intervir nessa vida. Além das suas criações, outros aspectos colocam ressonâncias entre aqueles que são os companheiros de elaboração deste exercício de pensamento. Suas intenções de pensar a vida, a realidade, o cotidiano sem se aproximar das formas experimentadas por pensamentos representativos. Ou seja, assim como aprendemos com Deleuze (2010), em seu texto Um manifesto de Menos, a crítica aqui realizada sobre a educação não se converte em apontar seus defeitos, mas expressa vontade e prazer em ter relações com o que é da ordem do inesperado. A vontade de ler, escrever, ouvir e tocar - e por 
que não dizer professorar - em formas ainda não inauguradas. Formas que estão diretamente ligadas ao esvaziamento das forças de poder que atuam nos espaços educacionais. Poder que se manifesta através das concepções sobre infância, sobre práticas docentes; entendimentos sobre a música e suas possíveis relações com os espaços de educação; escolhas das músicas e outros aspectos que produzem uma forma de confinamento das regras de convívio social e educacional, negando a possibilidade de reinvenção, não só das músicas, como também das pessoas. A (des)educação musical não deseja explicar, informar, mas produzir modos de existência que passam por meios como música, infância, educação, que podem ser experimentados através da arte, aqui entendida como forma de pensar. No entanto, os intercessores escolhidos não se referem somente aos grandes compositores, artistas ou pessoas que têm reconhecimento na história da humanidade pelo que suas obras produziram nos homens e mulheres do seu e de outros tempos. São intercessores aqueles que normalmente não tem voz. Aqueles que vivem suas vidas vividas na imanência de um cotidiano comum, simples, e que por suas simplicidades e desapegos são criadores de obras tão intensas quanto a dos grandes artistas.

Para realizar esta escritura são convidados, entre outros, Gilles Deleuze e Félix Guattari, que através de sua obra nos propõem uma (des)ordem nas formas de entender a filosofia e trazem para a cena principal, entre outras forças, a arte entendida como uma das formas escolhidas pela humanidade para realizar suas criações, seus pensamentos; Jonh Cage, músico, compositor e escritor, que tem como característica principal de sua produção problematizar as escolhas feitas pelo ocidente, compondo uma música inédita e pautada por valores diferentes daqueles que normalmente foram escolhidos para as composições musicais ; Paul Valery que nos provoca a criar caminhos para as composições, fazendo uso dos pensamentos de grandes criadores. Pensar o pensamento dos compositores como forma de pensar a própria criação; Silvio Ferraz, professor, músico e compositor, que faz da sua escrita um plano de composição e faz em palavras o que é da ordem dos sons ; Sandra Corazza, professora e escritora que, ao tomar o pensamento da diferença como fonte principal de seus estudos, (des)equilibra currículos, infâncias e docências através das problematizações expressas por suas escrituras. Também são convidados a compor este ensaio aqueles que “já ouviram as quatro estações, sabem do verão porque gostam de empinar pipas, sabem da primavera pelo mesmo motivo, sabem do inverno pelo simples fato do frio, sabem do outono porque é quando as folhas caem e que ainda deixam os olhos de qualquer um zonzos quando 
colocam seus dedos num pandeiro". O tratamento dado à realização desta escrita compartilha daqueles experimentados pela criação em arte. Enquanto lugar, escrever este trabalho segue os mesmos movimentos experimentados por quem conduz, dirige um plano de composição. Esta escritura se esforçou para que surgissem forças (des)educacionais, e que toda a música tratada, todos os elementos que compõem a educação pudessem ser (des)locados para o plano da (de)educação musical. Para tanto, o plano de composição (des)educacional é composto por forças heterogêneas que são colocadas em relação. As trocas estabelecidas entre estas forças permitem o surgimento de algo específico, singular, fruto da organização deste plano. Compõe este trabalho o desejo de escrever àqueles que têm pés descalços, mãos secas e sola de bicho-de-pé, que fazem sons com a boca e com pés descalços ladeira abaixo, tocam 4'33" sentados em carteiras. Mas também àqueles que sentados em suas carteiras se perguntam: $\mathrm{O}$ que, como, quando, por que e quem deseja uma outra relação entre Música, Infância e Educação? E no que se refere à infância, inventar outros lugares para estes seres, não só dentro das suas salas de aula, mas nas suas possibilidades de vida. Para isso, é vital se banhar com as forças das infâncias vividas e se valer do alimento produzido pelas suas invenções. Tomar essas possibilidades para construir um método que sustente o caminho a ser percorrido como a própria obra de arte. O fim não é mais o lugar de maior importância. A criação é, sobretudo, o caminho percorrido, é o pensamento sendo pensado. Desse método retirar o que salta, o inusitado e perceber que o instrumento é tão cúmplice do músico enquanto o músico é do instrumento. Inventar novas perguntas para que novas relações entre os elementos musicais possam ser experimentadas; entre estas, a invenção de novas formas de execução e produção sonoras. E por que não arriscar a elaboração de conceitos que ajudem a elaborar esta (des)ducação Musical?

O que liga todos esses elementos? A criação como condutora da elaboração desta escritura; o pensamento da diferença enquanto campo conceitual escolhido para sustentar as escolhas de realização de uma intervenção no mundo da educação através da invenção, da escritura, músicas e educações. E ainda, a alegria de ter a música e a infância como meios para realizar uma vida que ainda está por vir.

\title{
INQUIRY OF A MUSIC (UN)EDUCATION
}

\author{
Abstract


INVENTÁRIO DE UMA (DES)EDUCAÇÃO MUSICAL

This inquiry is an object of PhD thesis named By a Music (Un) Education carried out in the Education Graduate Program of Federal University of Rio Grande do Sul in December 2011. On the other hand, this work also make the Education Observatory Escrileituras - One Way to Read and Write in the Midst of Life, a project approved at 038/2010 public notice - MEC Education Observatory joined to CAPES and INEP with general coordination executed by Prof. Dr. ${ }^{a}$ Sandra Mara Corazza. The essay has un as prefix for act of creation and it makes available to intertwined propositions with Music Education having the Philosophy of Difference as intercessor and driving of compositional process associated to Music and Music Education.

Keywords: Music Education; Music, Education

\section{INVENTARIO DE UNA (DES)EDUCACIÓN MUSICAL}

\section{Resumen}

Ese inventario hace la composición de la Tese de Doctorado Por una (Des)Educación Musical, trabajo defendido en el programa de Pós Graduación en Educación da la Universidad Federal del Rio Grande del Sur en diciembre de 2011. El trabajo tanbién hace parte del Observatorio de la Educación Escrilecturas - Una manera de leer y escrivir en medio a la vida, proyeto aprovado en edital 038/2010 - Observatório da Educação do MEC, encuadernado al CAPES y al INEP. La Coordinación General és de la Prof. Dr. ${ }^{a}$ Sandra Mara Corazza. La prueba elige el prefijo (des) como un acto de creación y ló pomne a la disposición del proposiciones entrelazados con la Educación Musical, tomando la filosofía del Diferencia como intercesor y conducción de procesos composicionales conectados a la Música y a la Educación Musical.

Palabras claves: Educación Musical; Musica; Educación

\section{REFERÊNCIAS}

BARROS, Manoel de. Memórias inventadas: a infância. São Paulo: Planeta, 2003. 
DELEUZE, Gilles. Sobre o Teatro: um manifesto de menos; O esgotado. Tradução de Fátima Saadi, Ovídio de Abreu e Roberto Machado. Rio de Janeiro: Jorge Zahar Ed., 2010. Diferença e repetição. Tradução de Luiz Orlandi e Roberto Machado. Rio de Janeiro: Editora Graal, 2006.

DELEUZE, Gilles; GUATTARI, Félix. Kafka: por uma literatura menor. Tradução de Júlio Castañon Guimarães. Rio de Janeiro: IMAGO EDITORA LTDA, 1977.

O que é a Filosofia. Tradução: Bento Prado Junior e Alberto Alonso Munhos. São Paulo: Editora 34, 1992.

FERRAZ, Silvio. O livro das sonoridades [notas dispersas sobre composição]: um livro de música para não-músicos para músicos. Rio de Janeiro: Editora 7 Letras, 2005.

MACHADO, Roberto. Introdução. In: Sobre o teatro: um manifesto de menos; O esgotado. Tradução de Fátima Saadi, Ovídio de Abreu e Roberto Machado. Rio de Janeiro: Jorge Zahar Ed., 2010.

NIETZSCHE, Friedrich. Humano demasiado humano. Tradução de Carlos Vergara. Buenos Aires: Bilbioteca EDAF, 1984.

STASI, Carlos Eduardo Di. Representantions of music scrapers: the disjuncture between and complex in the study of a percussion instrument. University of Natal. Durban, 1999.

VALÉRY, Paul. Introdução ao método de Leonardo da Vinci. Tradução de Geraldo Gerson de Souza. São Paulo: Ed. 34. 1998.

WISNIK, José Miguel. $O$ som e o sentido: uma outra história das músicas. São Paulo: Companhia das Letras, 1989. 